Check for updates

Cite this: RSC Adv., 2019, 9, 21086

Received 21st May 2019

Accepted 6th June 2019

DOI: $10.1039 / c 9 r a 03822 a$

rsc.li/rsc-advances

\section{Two zinc(II) coordination polymers based on flexible co-ligands featuring assembly imparted sensing abilities for $\mathrm{Cr}_{2} \mathrm{O}_{7}{ }^{2-}$ and $0-\mathrm{NP} \uparrow$}

\author{
Meili Zhang, (D) Yanjin Zheng, Min Liu, Yixia Ren, (D)* Zhixiang Wang, Jia Cao \\ and Jijiang Wang $\mathbb{D}$
}

Two new Zn(॥) coordination complexes, formulated as [Zn(opda)(pbib)] (1) and [Zn(ppda)(pbib)( $\left.\left.\mathrm{H}_{2} \mathrm{O}\right)\right](2)$, $\left(\mathrm{H}_{2} \mathrm{opda}=1,2\right.$-phenylenediacetic acid, $\mathrm{H}_{2}$ ppda $=1,4$-phenylene-diacetic acid, pbib $=1,4$-bis $(1-$ imidazoly)benzene), have been synthesized. The opda ligands extend a 1D chain containing (Zn-pbib) polymer chains into a 2D layer in 1. In 2, the ppda ligands link Zn(॥) atoms to form a 2D network, then the rigid bis(imidazole) ligands give rise to the 3D structure. The fluorescence property application and mechanisms of two complexes for detecting $\mathrm{Cr}_{2} \mathrm{O}_{7}{ }^{2-}$ and $\mathrm{O}-\mathrm{NP}$ have been researched. For two complexes, the high quenching percentage in low concentration aqueous solution are $95.75 \%\left(\mathrm{Cr}_{2} \mathrm{O}_{7}{ }^{2-}\right.$, 1), $95.28 \%\left(\mathrm{Cr}_{2} \mathrm{O}_{7}{ }^{2-}, 2\right)$ and $97.56 \%$ (o-NP, 1), 96.59\% (o-NP, 2). Compared with 2, complex 1 has higher quenching percentage, this could be because 1 is a $3 \mathrm{D}$ supramolecular with a large hole. The detection

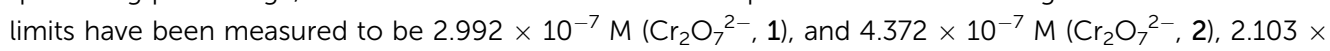
$10^{-7} \mathrm{M}(\mathrm{o}-\mathrm{NP}, 1), 1.862 \times 10^{-7} \mathrm{M}(\mathrm{o}-\mathrm{NP}, 2)$, respectively. The emissions of two complexes could be effectively and selectively quenched by $\mathrm{O}-\mathrm{NP}$ and $\mathrm{Cr}_{2} \mathrm{O}_{7}{ }^{2-}$, showing their potential as multi-responsive luminescent sensors.

\section{Introduction}

Metal organic frameworks (MOFs) are crystalline solids constructed via self-assembly of metal cations and organic ligands containing multiple binding sites, forming two or three dimensional extended coordination networks. They have been extensively studied for their rich structural chemistry ${ }^{1-5}$ and potential applications in numerous areas, gas storage and separations, optical waveguides, catalysis, luminescence, sensing, and energy storage conversion. ${ }^{6-19}$ Among these applications, fluorescent sensing based on fluorescent MOFs shows great promise due to its short response time, excellent sensitivity, operability and reusability. ${ }^{20-22}$ Selective sensing is very important for the control of environmental pollution and human health. In recent years, a variety of fluorescent MOFs was designed and applied for sensing of different types of environmental pollution analyses, including small molecules, metal cations, inorganic and organic anions, solvents, gases,

Department of Chemistry and Chemical Engineering, Laboratory of New Energy \& New Function Materials, Yan'an University, Yan'an, Shaanxi 716000, P. R. China. E-mail: ydzml2332041@163.com; Renyixia1@163.com; Fax: +86 911-2332037; Tel: +86 9112332037

$\dagger$ Electronic supplementary information (ESI) available. CCDC 1895715 and 1895714. For ESI and crystallographic data in CIF or other electronic format see DOI: $10.1039 / \mathrm{c} 9 \mathrm{ra} 03822 \mathrm{a}$ explosives and so on..$^{23,24}$ The detection mechanism is generally based on the quenching of the luminescence of MOFs.

Organic ligands play a very important role in design and preparation of fluorescent coordination polymers. The organic ligands often contain aromatic or conjugated $\pi$ moieties that are subject to excitation, giving rise to optical emission or photoluminescence (PL) upon irradiation. ${ }^{25}$ The multi-carboxyl and bis(imidazole) organic ligands containing aromatic or conjugated $\pi$ moieties have been employed in many reported fluorescent coordination polymers. ${ }^{26-29}$ In our recent works, a series of fluorescent coordination polymers based on flexible phenylenediacetate and different bis(imidazole) ligands have also been successfully obtained..$^{30-32}$ However, there is little research on relevant fluorescent probe sensors, and only a few $\mathrm{Zn} / \mathrm{Cd}-\mathrm{MOF}$ has been used as fluorescent probe sensors to detect metal ions, nitroaromatics, and other pollutants. ${ }^{33-35}$ So $\mathrm{Zn} / \mathrm{Cd}-\mathrm{MOF}$ s could be potential excellent sensitivity fluorescence sensor materials and need to be studied further. In this work, we adopt two similar fluorescent flexible phenylenedicarboxyl ligands $\left(\mathrm{H}_{2} \mathrm{Opda}\right.$ and $\mathrm{H}_{2}$ ppda) as the main ligands, accompanied by a N-donor bis(imidazole) ligand (pbib), to construct two new Zn-MOFs [Zn(opda)(pbib)] (1), $\left[\mathrm{Zn}(\mathrm{ppda})(\mathrm{pbib})\left(\mathrm{H}_{2} \mathrm{O}\right)\right]$ (2). Furthermore, their luminescent properties and sensing behaviors have also been investigated in water solution. The as-synthesized samples of these MOFs could be used directly as nitrophenol and dichromate sensors because of their sensitive and specific fluorescence response to 
nitrophenol and dichromate. With the comparison among two complexes and free ligands, we show that the formation of the MOFs structure is beneficial to their luminescence and sensing behaviors.

\section{Experimental section}

\section{General procedures}

Commercially obtained reagents and solvents were used. The hydrothermal reaction were performed in a $25 \mathrm{~mL}$ Teflon-lined stainless steel autoclave under autogenous pressure. The IR spectra were recorded as $\mathrm{KBr}$ pellets on a Nicolet Avatar-360 spectrometer in the range of 4000 to $400 \mathrm{~cm}^{-1}$. Elemental analyses for $\mathrm{C}, \mathrm{H}$, and $\mathrm{N}$ were carried out on a Flash 2000 elemental analyzer. Thermal gravimetric analyses (TGA) were carried out on a SDT Q600 thermogravimetric analyzer. A platinum pan was used for heating the sample with a heating rate of $10{ }^{\circ} \mathrm{C} \min ^{-1}$ under a $\mathrm{N}_{2}$ atmosphere. Fluorescent spectra were recorded with a Hitachi F4500 fluorescence spectrophotometer at room temperament equipped with a xenon lamp. Both excitation and emission band passes were set at $5 \mathrm{~nm}$. Powder X-ray diffraction (PXRD) measurements were performed on a Bruker D8-ADVANCE X-ray diffractometer with $\mathrm{Cu} \mathrm{K} \alpha$ radiation $(\lambda=$ $1.5418 \AA$ ) . Simulation of the XRPD spectra were carried out by the single-crystal data and diffraction-crystal module of the Mercury (Hg) program.

\section{Synthesis of complex [Zn(opda)(pbib)] (1)}

A mixture of opda $(0.0096 \mathrm{~g}, 0.05 \mathrm{mmol}), \mathrm{Zn}\left(\mathrm{NO}_{3}\right)_{2} \cdot 6 \mathrm{H}_{2} \mathrm{O}$ $(0.0297 \mathrm{~g}, 0.1 \mathrm{mmol}), \mathrm{H}_{2}$ pbib $(0.0210 \mathrm{~g}, 0.1 \mathrm{mmol})$ and $\mathrm{KOH}$ $(0.056 \mathrm{~g}, 0.1 \mathrm{mmol})$ were added to water $(12 \mathrm{~mL})$ in a $25 \mathrm{~mL}$ Teflon-lined stainless steel vessel. The mixture was heated at $150{ }^{\circ} \mathrm{C}$ for $72 \mathrm{~h}$. After the reactive mixture was slowly cooled to room temperature, colourless block crystals of 1 were obtained (yield: $45 \%$ based on $\mathrm{Zn}$ ). Elemental analysis calcd (\%) for $\mathrm{C}_{22} \mathrm{H}_{20} \mathrm{~N}_{4} \mathrm{O}_{5} \mathrm{Zn}$ : C 54.39, H 4.15, N 11.53; found (\%): C 54.28, $\mathrm{H}$ 4.12, N 11.45. IR ( $\mathrm{KBr}$ pellet, $\nu / \mathrm{cm}^{-1}$ ): $3141 \mathrm{w}, 2379 \mathrm{w}, 1608 \mathrm{~s}$, 1577 s, 1519 m, 1396 m, 1352 s, 1112 m, 1026 w, 950 m, 853 m, $654 \mathrm{~s}$.

\section{Synthesis of complex [Zn(ppda)(pbib) $\left.\left(\mathrm{H}_{2} \mathrm{O}\right)\right]$ (2)}

Complex $\mathbf{2}$ was synthesized by a procedure similar to that of $\mathbf{1}$, except $\mathrm{H}_{2}$ ppda $(0.0238 \mathrm{~g}, 0.1 \mathrm{mmol})$ replaced $\mathrm{H}_{2}$ opda. Colourless block crystals of 2 were obtained (yield: $43 \%$ based on $\mathrm{Zn}$ ). Elemental analysis calcd (\%) for $\mathrm{C}_{22} \mathrm{H}_{18} \mathrm{~N}_{4} \mathrm{O}_{4} \mathrm{Zn}$ : C 56.48, $\mathrm{H}$ 3.88, N 11.98; found (\%): C 56.32, H 3.80, N 11.85. IR ( $\left.\mathrm{cm}^{-1}\right)$ : 3455 m, 3128 m, 2379 w, 1616 s, 1526 m, 1367 s, 1283 m, 1237 m, 1089 s, 951 m, 837 w, 712 s.

\section{Crystal structural determination}

X-ray single-crystal diffraction data for two complexes were collected on a Bruker Smart 1000 CCD area-detector diffractometer with Mo-K $\alpha$ radiation $(\lambda=0.71073 \AA)$ by $\omega$ scan mode. The crystal structure was solved by direct methods, using SHELXS-2014 and least-squares refined with SHELXL-2014 using anisotropic thermal displacement parameters for all non-hydrogen atoms. ${ }^{36,37}$ Metal atoms were located from the Emaps and the other non-hydrogen atoms were located in successive difference Fourier syntheses and refined with anisotropic thermal parameters on $F^{2}$. Further details for structural analysis are summarized in Table 1.

\section{Fluorescent probe detection experiment}

Preparation of solutions. Firstly, finely ground sample of crystalline complex 1 and $2(20 \mathrm{mg}$, respectively) were placed in $100 \mathrm{~mL}$ water, treated by ultrasonication for $5 \mathrm{~h}$. The aqueous solution of complexes $\mathbf{1}$ and $\mathbf{2}$ were allowed to stand for 3 days to form a stable suspension. Secondly, stock solutions of metal anion salts $\left(\mathrm{X}=\mathrm{P}_{2} \mathrm{O}_{7}{ }^{4-}, \mathrm{HCO}_{3}{ }^{2-}, \mathrm{SCN}^{-}, \mathrm{SiO}_{3}{ }^{2-}, \mathrm{C}_{2} \mathrm{O}_{4}{ }^{2-}, \mathrm{SO}_{4}{ }^{2-}, \mathrm{SO}_{3}{ }^{2-}\right.$, $\mathrm{CH}_{3} \mathrm{COO}^{-}, \mathrm{ClO}_{4}{ }^{-}, \mathrm{Br}^{-}, \mathrm{Cl}^{-}, \mathrm{S}_{2} \mathrm{O}_{3}{ }^{2-}, \mathrm{CrO}_{4}{ }^{2-}, \mathrm{IO}_{3}{ }^{-}, \mathrm{H}_{2} \mathrm{PO}_{4}{ }^{2-}$, $\mathrm{MoO}_{4}{ }^{2-}, \mathrm{Cr}_{2} \mathrm{O}_{7}{ }^{2-}, \mathrm{Na}_{n} \mathrm{X}$ or $\left.\mathrm{K}_{n} \mathrm{X}, n=1,2,4\right)$; and organic small molecules (acetonitrile, $n$-propanol, $\mathrm{CCl}_{3}$, cyclohexane, methyl, ethyl acetate, $\mathrm{CCl}_{2}$, ethyl ether, benzene, isopropanol, aniline, phenol, $o$-xylene, DMF, $o$-NP) were prepared using ethanol at a concentration of $1 \mathrm{mM}$, respectively. Two milliliters of the prepared aqueous solutions of complexes $\mathbf{1}$ and $\mathbf{2}$ were used for the initial luminescence spectra and fluorescence experiments. Adding metal anion salts or organic small molecules to the prepared aqueous solutions of complexes $\mathbf{1}$ and $\mathbf{2}$ each time. We obtained the relationship between the quenching rate and the added quantity of $\mathrm{Cr}_{2} \mathrm{O}_{7}{ }^{2-}$ or $o$-NP solutions. The suspension was stirred at a constant rate during the experiment to maintain homogeneity.

\section{Results and discussion}

\section{Synthesis and characterization}

The employment of mixed-ligands strategy has been proven a feasible method to construct new complexes structures and functional applications. However, the direct mixing of the solutions of metal salts and organic ligands usually results in

Table 1 Crystallographic data and details of diffraction experiments for complexes 1 and 2

\begin{tabular}{lll}
\hline Complex & $\mathbf{1}$ & $\mathbf{2}$ \\
\hline Empirical formula & $\mathrm{C}_{22} \mathrm{H}_{20} \mathrm{~N}_{4} \mathrm{O}_{5} \mathrm{Zn}$ & $\mathrm{C}_{22} \mathrm{H}_{18} \mathrm{~N}_{4} \mathrm{O}_{4} \mathrm{Zn}$ \\
Formula weight & 485.82 & 467.81 \\
Crystal system & Monoclinic & Monoclinic \\
Space group & $P{ }_{1} / n$ & $P 22_{1} / n$ \\
$a(\AA)$ & $12.474(3)$ & $11.8375(9)$ \\
$b(\AA)$ & $13.755(3)$ & $12.1648(9)$ \\
$c(\AA)$ & $12.771(3)$ & $13.9559(10)$ \\
$\alpha\left({ }^{\circ}\right)$ & 90 & 90 \\
$\beta\left({ }^{\circ}\right)$ & $105.090(3)$ & $102.868(10)$ \\
$\gamma\left({ }^{\circ}\right)$ & 90 & 90 \\
$V\left(\AA^{3}\right)$ & $2115.6(7)$ & $1959.2(3)$ \\
$Z$ & 4 & 4 \\
$\rho\left(\mathrm{g} \mathrm{cm}^{-3}\right)$ & 1.5252 & 1.5859 \\
$\mu\left(\mathrm{mm}^{-1}\right)$ & 1.625 & 1.1425 \\
$R_{\text {int }}$ & 0.0144 & 0.0130 \\
$\mathrm{Goodness}^{\circ}$ of-fit on $F^{2}$ & 1.0371 & 1.0468 \\
$R_{1}{ }^{a} / w R_{2}{ }^{b}[I>2 \sigma(I)]$ & $0.0474 / 0.1516$ & $0.0571 / 0.2030$ \\
$R_{1}{ }^{a} / w R_{2}{ }^{b}$ (all data) & $0.0513 / 0.1570$ & $0.0609 / 0.2071$ \\
${ }^{a} R_{1}=\Sigma|| F_{\mathrm{o}}|-| F_{\mathrm{c}}|| \Sigma\left|F_{\mathrm{o}}\right| .^{b}$ & $w R_{2}=\left[\Sigma w\left(F_{\mathrm{o}}{ }^{2}-F_{\mathrm{c}}{ }^{2}\right)^{2} / \Sigma w\left(F_{\mathrm{o}}{ }^{2}\right)^{2}\right]^{1 / 2}$.
\end{tabular}




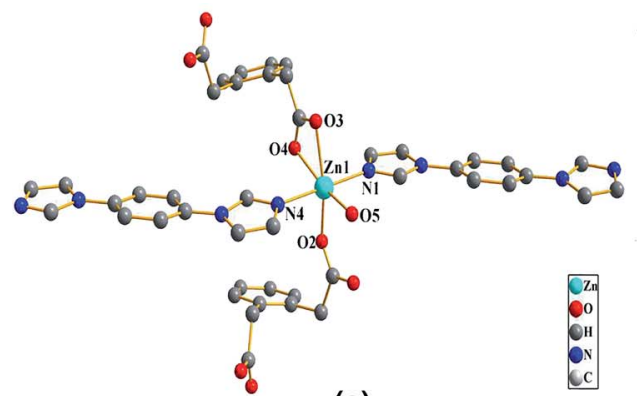

(a)

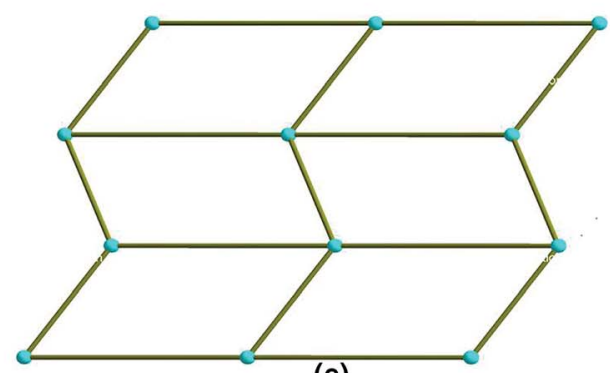

(c)

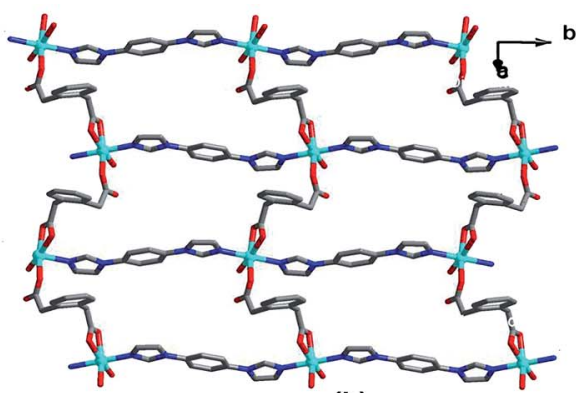

(b)

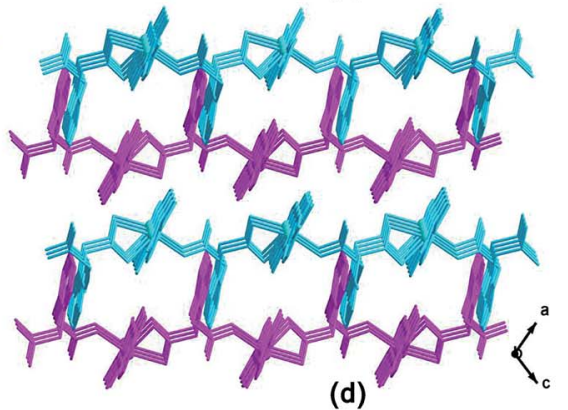

(d)

Fig. 1 (a) Coordination environment of the Zn(I) ion in 1. All hydrogen atoms are omitted for clarity. (b) Ball-and-stick view of the 2D layer along ab plane. (c) Schematic view of the $(4,4)$ net in 1 (green nodes for 4 -connected $\mathrm{Zn}(\mathrm{I})$ atoms) (d) view of the 3D network of 1 extended by the 2D layers in an offset stacking fashion.

precipitations that are difficult to be structurally characterized. To overcome this problem, hydrothermal method was applied in this study, which has been proven to be a powerful approach for the preparation of various crystalline materials. Complexes 1 and $\mathbf{2}$ are stable in air and common solution. The IR spectra usually show features attributable to each component of the complexes. The broad bands centered at $3455 \mathrm{~cm}^{-1}$ for complex 2 can be assigned to the coordination water molecule. The characteristic bands of carboxylate groups in complexes 1-2 appeared in the usual region at $1616-1526 \mathrm{~cm}^{-1}$ for the antisymmetric stretching vibrations and at $1519-1367 \mathrm{~cm}^{-1}$ for the symmetric stretching vibrations.

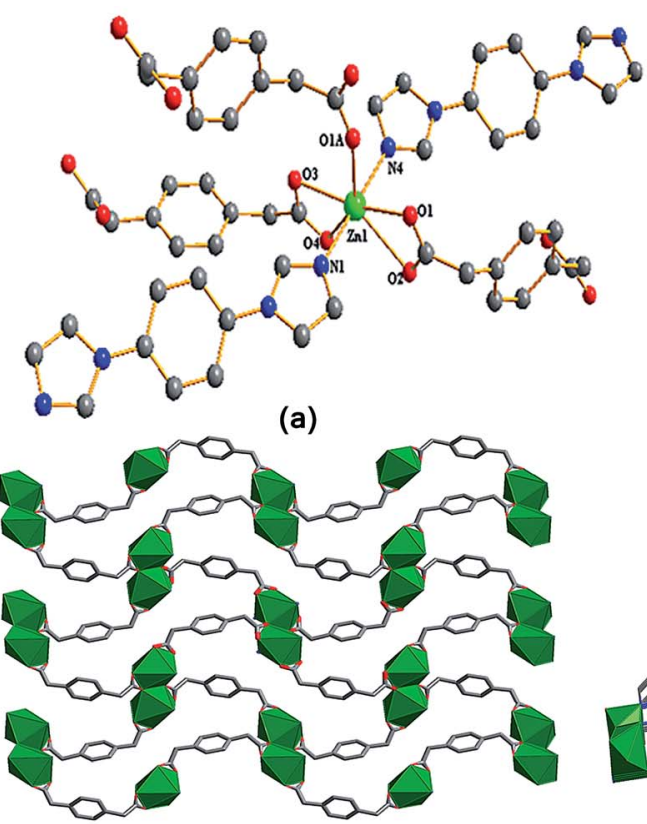

(c)

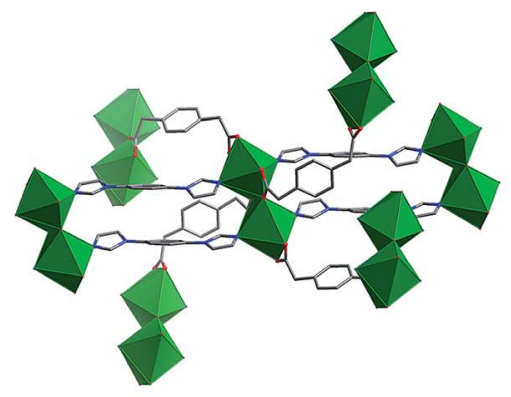

(b)

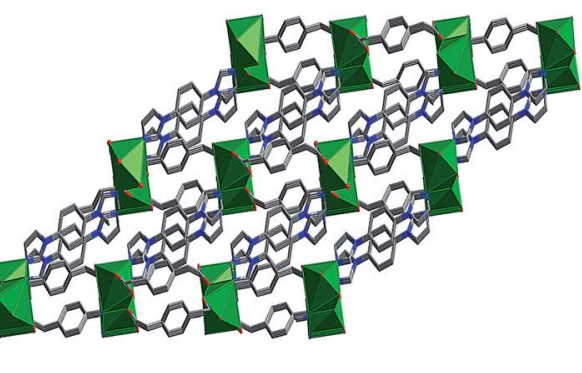

(d)

Fig. 2 (a) Coordination environment of the $Z n(I)$ ion in 2 . All hydrogen atoms are omitted for clarity. Symmetry codes: $A=1-x, 1-y, 1-z$. (b) The six-connected binuclear Zn(II). (c) Ball-and-stick view of the 2D layer. (d) View of the 3D framework of 2. 


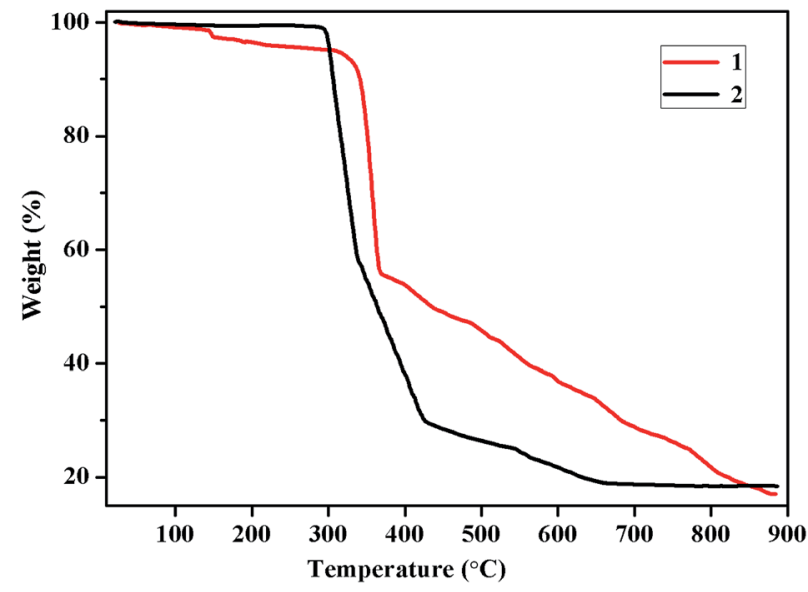

Fig. 3 Thermal gravimetric analysis (TG) plot of complexes 1-2.

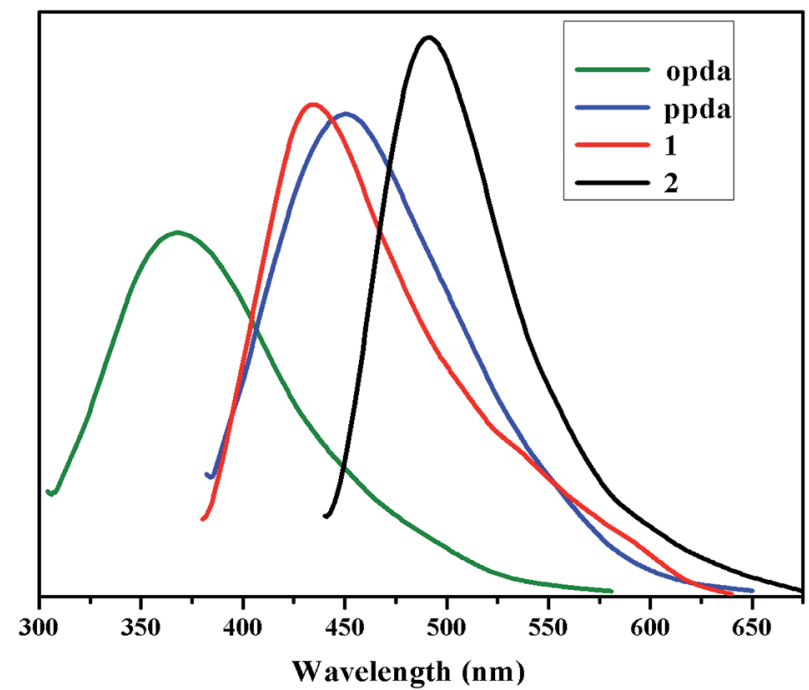

Fig. 4 Solid-state fluorescent emission spectra of complexes 1-2, free opda and ppda ligands at room temperature.

\section{Structure description of complexes}

Crystal structure of [Zn(opda)(pbib)] (1). Single-crystal X-ray diffraction analysis reveal that complex 1 crystallizes in monoclinic system, $P 2_{1} / n$ space group. The asymmetric unit of 1 comprises one crystallographically independent $\mathrm{Zn}$ (II) atom, one opda and one pbib ligand. As shown in Fig. 1a, the central $\mathrm{Zn}$ (II) atom has a distorted octahedral coordination geometry, coordinated by two nitrogen atoms of two different opda ligands $[\mathrm{Zn}(1)-\mathrm{N}(1)=2.122(2)$ and $\mathrm{Zn}(1)-\mathrm{N}(4)=2.129(2) \AA]$ and four oxygen atoms from two different opda ligands and one water molecule $[\mathrm{Zn}(1)-\mathrm{O}(2)=2.056(3), \mathrm{Zn}(1)-\mathrm{O}(3)=3.224(2)$, $\mathrm{Zn}(1)-\mathrm{O}(4)=2.208(2)$ and $\mathrm{Zn}(1)-\mathrm{O}(5)=2.160(2) \AA]$. In the structure of 1 , both of opad and pbib ligands performs as a bridging to join up adjacent $\mathrm{Zn}$ (II) atoms giving rise to a corrugated 2D $(4,4)$ layer with rectangular windows of $12.32 \times$ $19.45 \AA$ viewed along $a b$ plane (Fig. 1b). Adjacent layers are stacked in an offset fashion with an $\mathrm{ABAB}$ sequence to propagate into a 3D supramolecular mesomer network through
$\mathrm{O}-\mathrm{H} \cdots \mathrm{O}$ hydrogen bonds (O5-H5a $\cdots$ O3A, O5 $\cdots$ O3A: $2.013 \AA$ ) between carboxylate groups and water molecule of different layers. And weak $\mathrm{C}-\mathrm{H} \cdots \pi$ interactions between two benzene rings of opda ligands $(\mathrm{C} 3-\mathrm{H} 3 \cdots \pi, \mathrm{C} \cdots \pi$ seperation $4.035 \AA$ measured from $\mathrm{C} 3$ to the centroid of the benzene ring in opda ligand) can also be observed. While the 3D supramolecular has holes with $10.22 \times 10.89 \AA$ window viewed along ac plane (Fig. 1d).

Crystal structure of $\left[\mathrm{Zn}(\mathbf{p p d a})(\mathrm{pbib})\left(\mathrm{H}_{2} \mathrm{O}\right)\right]$ (2). When the flexible ppda building block was used, the 3D polymeric structure of 2 can be isolated. The asymmetric unit consists of one $\mathrm{Zn}$ (II) ion, one ppda ligand and one pbib ligand. As shown in Fig. 2a, the $\mathrm{Zn}$ (II) ion is seven-coordinated in $\left\{\mathrm{ZnO}_{5} \mathrm{~N}_{2}\right\}$ pentagonal bipyramidal geometry, and $\mathrm{Zn}$ (II) is surrounded by $(\mathrm{O}(1), \mathrm{O}(2), \mathrm{O}(3), \mathrm{O}(4), \mathrm{O}(1 \mathrm{~A}))$ from three ppda ligands, and $(\mathrm{N}(1), \mathrm{N}(4 \mathrm{~A}))$ from two pbib ligands. The $\mathrm{Zn}-\mathrm{O}$ bond lengths vary from $2.350(5)$ to $2.514(3) \AA$, and the $\mathrm{Zn}-\mathrm{N}$ distances are within the range of 2.291(5)-2.297(5) A. All the bond lengths are consistent with those of the reported $\mathrm{Zn}$ (II) compound..$^{\mathbf{3 8} 39}$

In 1, the opda ligand has a trans-conformation with two carboxyl groups locating two sides of the benzene ring plan, which can be viewed as a linear building block. Interestingly, the ppda ligand in $\mathbf{2}$ shows a cis-conformation and acts as a "V" type building block. In 2, the carboxylate groups of ppda ligand adopt $\mu_{1}-\eta^{1}: \eta^{1}$ and $\mu_{2}-\eta^{2}: \eta^{1}$ coordination modes, respectively. They link a pair of $\mathrm{Zn}(\mathrm{II})$ ions to form $\left[\mathrm{Zn}_{2} \mathrm{O}_{8}\right]$ unit with the $\mathrm{Zn} \cdots$ $\mathrm{Zn}$ separation of $3.853 \AA$ (Fig. 2b). Each $\left[\mathrm{Zn}_{2} \mathrm{O}_{8}\right]$ unit is fused to four neighboring units by the ppda ligands with different orientation forming a $2 \mathrm{D}$ plane. Such polymeric planes are extended into a 3D framework by pbib ligands with a bismonodentate bridging mode.

The structural difference of two complexes are significantly effect by the coordination geometries of the central metal ions and the coordination modes, conformations of the organic ligands. Compared with ppda ligand, the two carboxyl groups of opda ligand have larger steric hindrance, so its dimensional performance of linking metal ions is weak. Therefore, two complexes exhibit a variety of architectures from 2D network (complex 1) to 3D framework (complex 2) due to different opda and ppda ligands.

\section{Thermal analysis and PXRD patterns}

In order to check the phase purity of two complexes for the further luminescent measurements, powder X-ray diffraction (PXRD) patterns of complexes 1-2 have been carried out at room temperature (Fig. S1 $\dagger$ ). The peak positions of the experimental PXRD patterns match well with the simulated one, indicating the single-phase of corresponding materials. To examine the thermal stability of complexes 1-2, thermal gravimetric analysis (TGA) experiments for complexes 1-2 were performed by heating the corresponding samples from room temperature to $900{ }^{\circ} \mathrm{C}$ with a heating rate of $10{ }^{\circ} \mathrm{C} \mathrm{min}^{-1}$ under a nitrogen atmosphere as shown in Fig. 3. In complex 1, the weight loss occurred from room temperature to $152{ }^{\circ} \mathrm{C}$ (obsd $3.46 \%$, calcd $3.70 \%$ ), which corresponds to the decomposition of framework structure on one coordinated water molecules. The TGA curve 

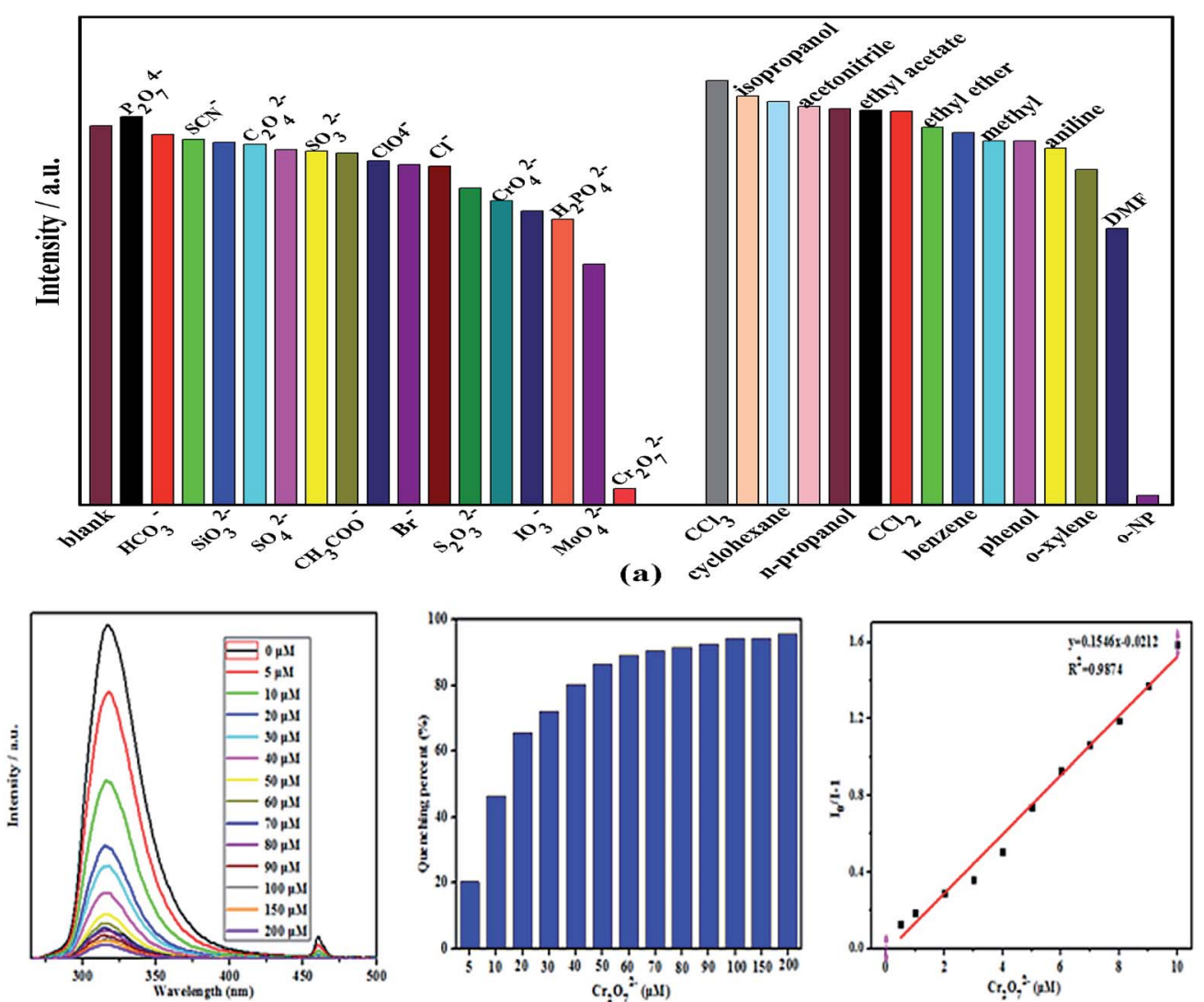

(b)
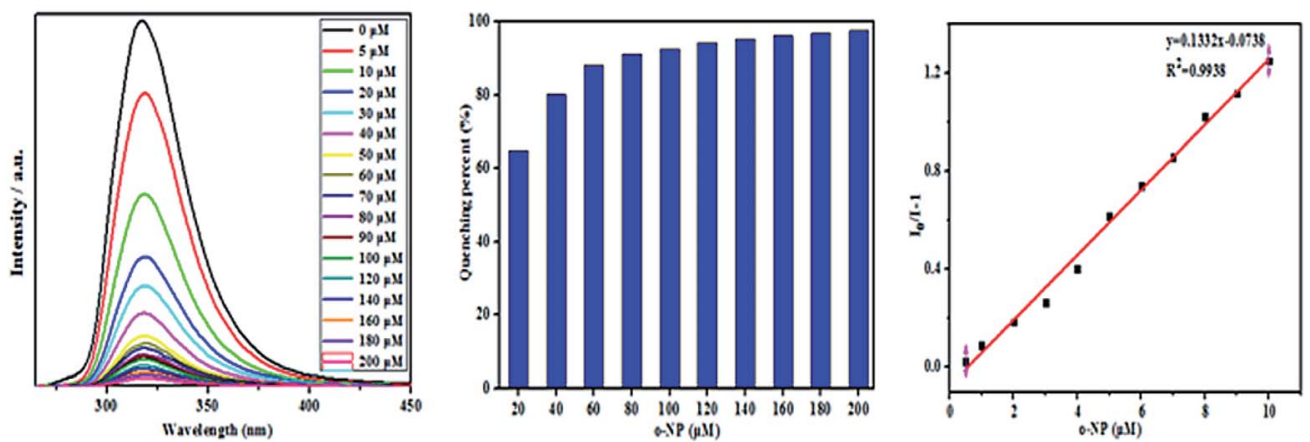

(c)

Fig. 5 (a) Luminous intensity of complex 1 ( $2 \mathrm{~mL}$, prepared solution) in aqueous solutions with different anions and organic small molecules (0.001 M). (b) Concentration-dependent luminescence quenching of complex 1 suspension in water by $\mathrm{Cr}_{2} \mathrm{O}_{7}{ }^{2-}$ (excited at $240 \mathrm{~nm}$ ), percentage of luminescence quenching, Stern-Volmer plot of complex 1 suspension quenched by $\mathrm{Cr}_{2} \mathrm{O}_{7}{ }^{2-}$. (c) Concentration-dependent luminescence quenching of complex 1 suspension in water by o-NP (excited at $240 \mathrm{~nm}$ ), percentage of luminescence quenching, Stern-Volmer plot of complex 1 suspension quenched by o-NP.

for complexes 1-2 suggested that two complexes can be stable up to $315,292{ }^{\circ} \mathrm{C}$, and the final residues are $\mathrm{ZnO}$ (obsd $17.02 \%$, calcd $16.76 \%$ ) of $1, \mathrm{ZnO}$ (obsd $18.43 \%$, calcd $17.31 \%$ ) of 2 , respectively.

\section{Luminescent properties}

Since complexes 1 and 2 are constructed with a $\mathrm{d}^{10}$ electron configured $\mathrm{Zn}^{2+}$ ion and fluorescent multi-carboxyl, bis(imidazole) organic ligands containing aromatic or conjugated $\pi$ moieties, it is highly possible for them to exhibit photoactivity. To examine the luminescent properties of these $\mathrm{d}^{10}$ metal complexes, the luminescence spectra of complexes 1 and 2, the free opda, ppda and pbib ligands have been measured at room temperature. As shown in Fig. 4, the free opda and ppda ligands display main emission peak at $368 \mathrm{~nm}\left(\lambda_{\text {ex }}=300 \mathrm{~nm}\right)$ and $451 \mathrm{~nm}\left(\lambda_{\mathrm{ex}}=375 \mathrm{~nm}\right)$ respectively. While the pbib ligand display main emission band at $380 \mathrm{~nm}\left(\lambda_{\mathrm{ex}}=310 \mathrm{~nm}\right)$, the emission intensities is relatively weak, so its curve does not appear in the graph. In contrast, the emission peak of complexes 1 [ $435 \mathrm{~nm}\left(\lambda_{\mathrm{ex}}\right.$ $=370 \mathrm{~nm})], 2\left[490 \mathrm{~nm}\left(\lambda_{\mathrm{ex}}=420 \mathrm{~nm}\right)\right]$, is red-shifted by 67 and 


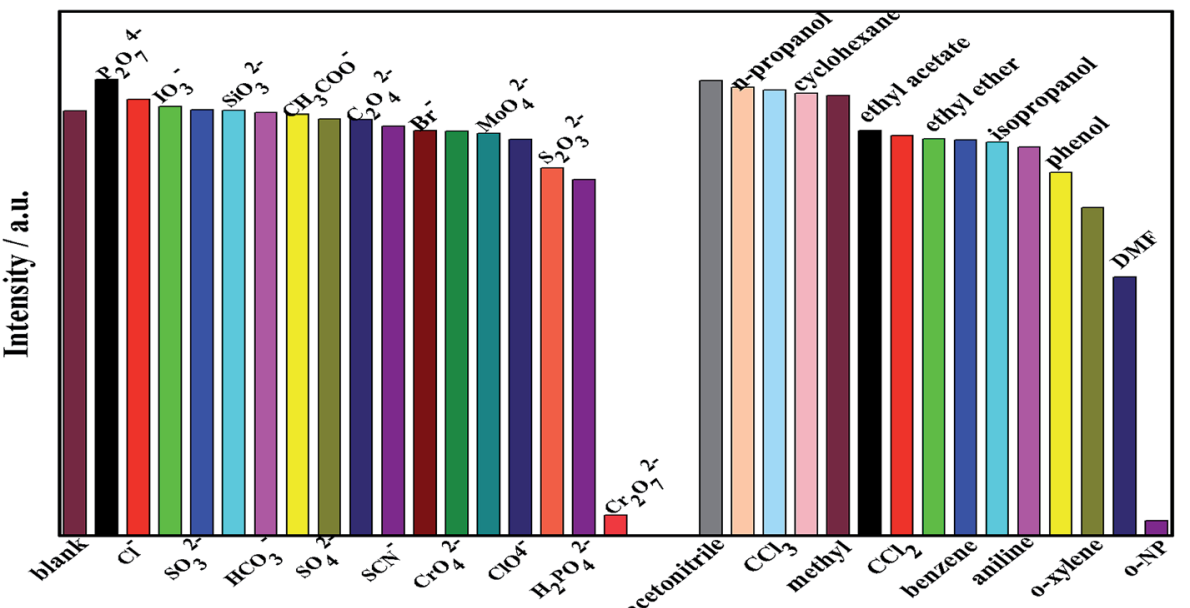

(a)
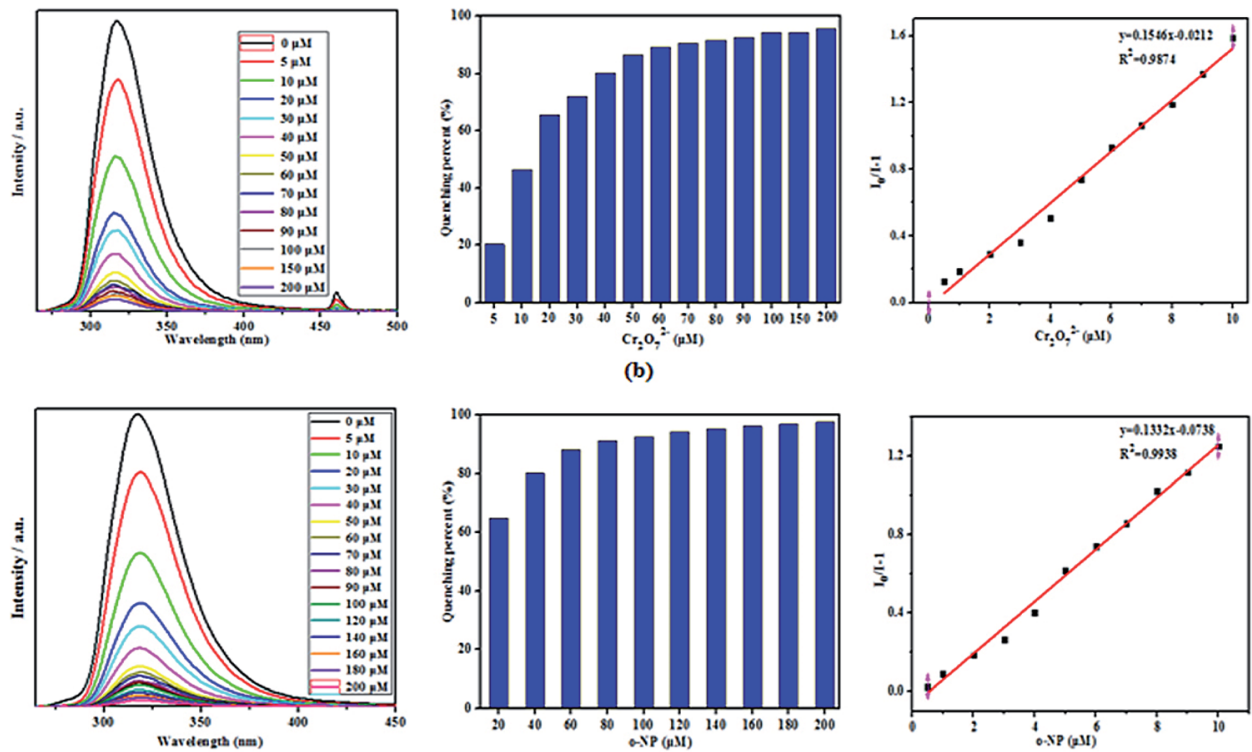

(c)

Fig. 6 (a) Luminous intensity of complex 2 ( $2 \mathrm{~mL}$, prepared solution) in aqueous solutions with different anions and organic small molecules (0.001 M). (b) Concentration-dependent luminescence quenching of complex 2 suspension in water by $\mathrm{Cr}_{2} \mathrm{O}_{7}{ }^{2-}$ (excited at $\left.240 \mathrm{~nm}\right)$, percentage of luminescence quenching, Stern-Volmer plot of complex 2 suspension quenched by $\mathrm{Cr}_{2} \mathrm{O}_{7}{ }^{2-}$. (c) Concentration-dependent luminescence quenching of complex 2 suspension in water by o-NP (excited at $240 \mathrm{~nm}$ ), percentage of luminescence quenching, Stern-Volmer plot of complex 2 suspension quenched by o-NP.

$39 \mathrm{~nm}$ relative to the opda and ppda ligands. The closeness in the emission wavelength between pda and the two complexes indicates that the photoluminescence of $\mathbf{1}$ and $\mathbf{2}$ could be mainly attributed to pda ligand centred electronic excitation perturbed by the $\mathrm{Zn}^{2+}$ ion and other components. These shifts of the emission bands can be attributed to the deprotonated effect of opda and the coordination interactions of the organic ligands to $\mathrm{Zn}$ (II) ions as well as $\mathrm{C}-\mathrm{H} \cdots \pi$ interactions in two complexes network..$^{\mathbf{4 0}}$ The emission intensities of $\mathbf{1}$ and $\mathbf{2}$ are much stronger than that of a free pda ligand, that is the formation of complexes enhances the fluorescence of the ligand. This phenomenon is a typical example of aggregation-induced emission (AIE) and may be explained with that the coordination to metal ions in a complexes restricted the deformation of the ligand and the induced nonradiative relaxation. ${ }^{\mathbf{4 1 , 4 2}}$

\section{Sensing of $\mathrm{Cr}_{2} \mathrm{O}_{7}^{2-}$ and $\mathrm{o}-\mathrm{NP}$}

Because of the excellent water stability and strong fluorescence of two complexes, their application in sensing/detecting ions in water system were explored. Firstly, the sensing/detecting ability of two complexes toward different anions were investigated by adding the aqueous solutions of $\mathrm{P}_{2} \mathrm{O}_{7}{ }^{4-}, \mathrm{HCO}_{3}{ }^{2-}$, $\mathrm{SCN}^{-}, \mathrm{SiO}_{3}{ }^{2-}, \mathrm{C}_{2} \mathrm{O}_{4}{ }^{2-}, \mathrm{SO}_{4}{ }^{2-}, \mathrm{SO}_{3}{ }^{2-}, \mathrm{AcO}^{-}, \mathrm{ClO}_{4}{ }^{-}, \mathrm{Br}^{-}, \mathrm{Cl}^{-}$, $\mathrm{S}_{2} \mathrm{O}_{3}{ }^{2-}, \mathrm{CrO}_{4}{ }^{2-}, \mathrm{IO}_{3}{ }^{-}, \mathrm{H}_{2} \mathrm{PO}_{4}{ }^{2-}, \mathrm{MoO}_{4}{ }^{2-}$, and $\mathrm{Cr}_{2} \mathrm{O}_{7}{ }^{2-}$ with $\mathrm{Na}^{+}$ or $\mathrm{K}^{+}$as counter cations into the suspension of two complexes (Fig. 5a and 6a). Interestingly, only $\mathrm{Cr}_{2} \mathrm{O}_{7}{ }^{2-}$ afforded a quite obvious luminescent quenching effect, with the percentage of quenching of complexes 1 and 2 being 95.75\% and $95.28 \%$, respectively (Fig. 5b and 6b). Secondly, the organic small molecules ethanol solution (acetonitrile, $n$-propanol, $\mathrm{CCl}_{3}$, 


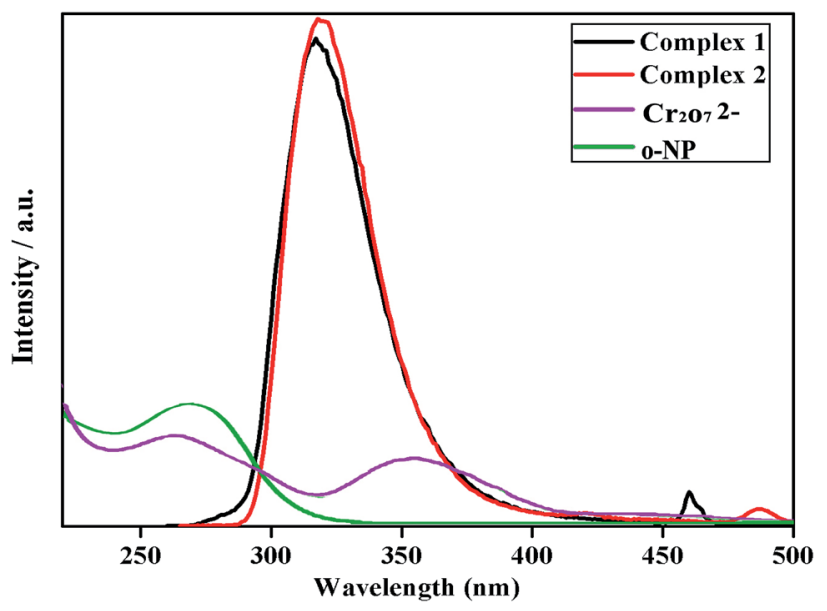

Fig. 7 Spectral overlap between the UV-vis absorption spectra of $\mathrm{Cr}_{2} \mathrm{O}_{7}{ }^{2-}$ and $0-\mathrm{NP}$ with the emission spectrum of complexes 1-2 in aqueous solution.

cyclohexane, methyl, ethyl acetate, $\mathrm{CCl}_{2}$, ethyl ether, benzene, isopropanol, aniline, phenol, $o$-xylene, DMF, $o$-NP) was added to the complexes $\mathbf{1}$ and $\mathbf{2}$ suspension to study the sensing/ detection ability of complexes $\mathbf{1}$ and $\mathbf{2}$ for different organic solvents (Fig. 5a and 6a). It was found that only $o$-NP had a very significant luminescence quenching effect, and the percentages of quenching of complexes 1 and 2 were $97.56 \%$ and $96.59 \%$, respectively (Fig. 5c and 6c). However, other anions or organic small molecules only led to slight fluorescent intensity change of complexes 1 and 2 suspension. Compared with complex 2, complex 1 has higher quenching percentage, this may be attributed to the higher adsorption capacity of complex 1 with larger holes (with $10.22 \times 10.89 \AA$ window).

In addition, competitive fluorescence titration experiments have been conducted, in which the emission intensity of complexes $\mathbf{1}$ and $\mathbf{2}$ were consecutively recorded upon the gradual addition of $\mathrm{Cr}_{2} \mathrm{O}_{7}{ }^{2-}$ aqueous solution or $o$-NP ethanol solution into its uniform aqueous suspension containing competing anions or small organic molecules. It should be noted that after $\mathrm{Cr}_{2} \mathrm{O}_{7}{ }^{2-}$ or $o$-NP were added to the above solution, the fluorescence was almost completely quenched. Therefore, complexes $\mathbf{1}$ and $\mathbf{2}$ have high sensitivity, selectivity, and resistance to interference from other coexisting ions in detecting $\mathrm{Cr}_{2} \mathrm{O}_{7}{ }^{2-}$ and $o$-NP in aqueous solution. More noteworthy is that the fluorescence intensity of the complexes 1 and 2 suspension significantly reduced in the first $1 \mathrm{~min}$ after $o$-NP was added and then retained an almost constant value, suggesting that the $o$-NP induced fluorescence quenching progress is very fast. These results indicate that complexes 1 and 2 can serve as a sensitive sensor for the selective and rapid detection of $\mathrm{Cr}_{2} \mathrm{O}_{7}{ }^{2-}$ and $o$-NP in water system.

Furthermore, we explored the quantitative detection ability of complexes 1 and 2 toward $\mathrm{Cr}_{2} \mathrm{O}_{7}{ }^{2-}$ or $o$-NP, respectively. Concentration-based quenching experiments were conducted by documenting the decrease of emission intensity of complexes 1 and 2 suspension upon the addition of $\mathrm{Cr}_{2} \mathrm{O}_{7}{ }^{2-}$ or $o$-NP, with incremental concentrations in the range of 5-200 $\mu \mathrm{M}$. These titration curves show that the emission intensities of complexes 1 and 2 decreases with increasing $\mathrm{Cr}_{2} \mathrm{O}_{7}{ }^{2-}$ or $o$-NP concentration (Fig. 5b and 6c).The fluorescent quenching efficiency was then quantitatively evaluated by the Stern-Volmer equation, $I_{0} / I=K_{\mathrm{sv}}[\mathrm{M}]+1$, where $I_{0}$ and $I$ are the maximum luminescent intensities before and after the addition of the probe, $[\mathrm{M}]$ is the molar concentration of probe solution, and $K_{\mathrm{sv}}$ is the quenching constant $\left(\mathrm{M}^{-1}\right) \cdot{ }^{43-47}$ As shown in Fig. $6 \mathrm{~b}$ and $\mathrm{c}$, the luminescen intensity of complexes $\mathbf{1}$ and 2 suspension quenched by $\mathrm{Cr}_{2} \mathrm{O}_{7}{ }^{2-}$ or $o$-NP well follow the equation in lower concentration range, with a nearly linear correlation. Complexes 1 and 2 present the highest $K_{\mathrm{sv}}$ values (complex 1: $K_{\mathrm{sv}}$ $\left(\mathrm{Cr}_{2} \mathrm{O}_{7}{ }^{2-}\right)=1.546 \times 10^{7} \mathrm{M}^{-1}, R^{2}=0.9874 ; K_{\mathrm{sv}}(o-\mathrm{NP})=1.332 \times$ $10^{7} \mathrm{M}^{-1}, R^{2}=0.9938$; complex 2: $K_{\mathrm{sv}}\left(\mathrm{Cr}_{2} \mathrm{O}_{7}^{2-}\right)=9.778 \times 10^{8} \mathrm{M}^{-1}$, $\left.R^{2}=0.9732 ; K_{\mathrm{sv}}(o-\mathrm{NP})=1.422 \times 10^{7} \mathrm{M}^{-1}, R^{2}=0.9907\right) \mathrm{Cr}_{2} \mathrm{O}_{7}{ }^{2-}$ or $o$-NP suggesting high quenching efficiency. The detection limits of $\mathrm{Cr}_{2} \mathrm{O}_{7}{ }^{2-}$ or $o$-NP were calculated using the equation: detection limit $=3 \sigma / K_{\mathrm{sv}}$ ( $\sigma$ is the standard deviation of fluorescent intensity of blank solution). Accordingly, the detection limits of complexes 1-2 for $\mathrm{Cr}_{2} \mathrm{O}_{7}{ }^{2-}$ or $o$-NP were calculated to be $2.992 \times 10^{-7} \mathrm{M}\left(\mathrm{Cr}_{2} \mathrm{O}_{7}{ }^{2-}\right.$, complex 1), $2.103 \times 10^{-7} \mathrm{M}\left(o-\mathrm{NP}\right.$, complex 1), $4.372 \times 10^{-7} \mathrm{M}$ $\left(\mathrm{Cr}_{2} \mathrm{O}_{7}{ }^{2-}\right.$, complex 2), $1.862 \times 10^{-7} \mathrm{M}$ (o-NP, complex 2), respectively. The quenching constants and detection limits of two complexes as fluorescent sensing materials for detecting $\mathrm{Cr}_{2} \mathrm{O}_{7}{ }^{2-}$ and $o$-NP surpass most of the reported CP-based fluorescent sensing materials $\left(\left[\mathrm{Zn}_{7}(\mathrm{TPPE})_{2}\left(\mathrm{SO}_{4}{ }^{2-}\right)_{7}\right]\left(\mathrm{DMFH}_{2} \mathrm{O}\right): 1.2 \times 10^{-6} \mathrm{M}\right.$ for $\mathrm{Cr}_{2} \mathrm{O}_{7}{ }^{2-},\left\{\mathrm{Cd}(2,6-\mathrm{NDC})\left(\mathrm{H}_{2} \mathrm{O}\right)\right\}_{n}: 9.2 \times 10^{-5} \mathrm{M}$ for $\left.o-\mathrm{NP}\right),{ }^{48,49}$ indicating the high sensitivity of complexes 1-2 for sensing $\mathrm{Cr}_{2} \mathrm{O}_{7}{ }^{2-}$ and $o$-NP. This result demonstrates that two complexes can be highly effective and selective luminescent sensors for $\mathrm{Cr}_{2} \mathrm{O}_{7}{ }^{2-}$ and $o$-NP, with improved or comparable performance to those of the reported $\mathrm{Zn} / \mathrm{Cd}-\mathrm{MOFs}$ probes.

In order to study the quenching mechanism of complexes 1-2 to detect $\mathrm{Cr}_{2} \mathrm{O}_{7}{ }^{2-}$ and $o$-NP, the UV-vis absorption of $\mathrm{Cr}_{2} \mathrm{O}_{7}{ }^{2-}, o$ $\mathrm{NP}$ and complexes 1-2 in aqueous solution was determined experimentally. The energy transfer mechanism can enhance the fluorescence quenching efficiency and improve sensitivity. Energy transfer mainly depends on the extent of overlap of the absorption spectrum of the acceptor and the excitation or emission of the donor (complexes). ${ }^{50-55}$ As shown in Fig. 7a, the UV-vis absorption spectrum of $\mathrm{Cr}_{2} \mathrm{O}_{7}{ }^{2-}$ and $o$-NP showed an extensive overlap with the emission spectrum of complexes 1-2 respectively. $\mathrm{Cr}_{2} \mathrm{O}_{7}{ }^{2-}$ ions have wide absorption bands (from 230 to $450 \mathrm{~nm}$ ) in the UV-vis region, which overlap with the emission bands of complexes 1-2. And $o$-NP can also be explained based on the photoinduced electron transfer mechanism. The nitro group of $o-\mathrm{NP}$ is an electron withdrawing substituent, the electron present in the excited state of complexes 1-2 is transferred to the LUMO of the electrondeficient $o$-NP, leading to fluorescence quenching of complexes 1-2. Thus, the predominant quenching mechanism of complexes 1-2 to detect $\mathrm{Cr}_{2} \mathrm{O}_{7}{ }^{2-}$ and $o$-NP are attributed to electron transfer.

\section{Conclusion}

In summary, two new zinc(II) coordination polymers based on the flexible phenylenedicarboxyl acid and bis(imidazole) 
ligands have been synthesized under hydrothermal conditions. Two complexes exhibit different architectures from 2D network (complex 1) to 3D framework (complex 2) due to different flexible $\mathrm{H}_{2}$ pda ligand. Two complexes have shown to be excellent discriminative probe for the highly selective and sensitive detection of $\mathrm{Cr}_{2} \mathrm{O}_{7}{ }^{2-}$ and $o$-NP based on their sensitive fluorescence quenching. The diversities of the structures for two complexes have some effects on the fluorescence properties to accelerate the quenching rate of $\mathrm{Cr}_{2} \mathrm{O}_{7}{ }^{2-}$ and $o$-NP, especially complex 1. The high quenching percentage and the low detection limit of $\mathrm{Cr}_{2} \mathrm{O}_{7}{ }^{2-}$ or $o$-NP may make complexes 1-2 excellent candidates for multi-responsive fluorescent probe materials.

\section{Conflicts of interest}

There are no conflicts to declare.

\section{Acknowledgements}

This work was financially supported by the National Natural Science Foundation of China (21573189), the Nature Scientific Foundation of the Shaanxi Province of China (2016XT-24), and the Yan'an University Undergraduate Training Programs of Innovation and Entrepreneurship (D2018010).

\section{Notes and references}

1 L. Xu, J. Yang, Y.-Y. Liu, G.-H. Xu and J.-F. Ma, J. Lumin., 2019, 209, 398-403.

2 J. Seco, P. Sonia, D. Briones, J. Garcia, J. Cepeda and A. Rodriguez-Dieguez, Cryst. Growth Des., 2017, 17, 38933906.

3 X.-Y. Liu, F.-F. Li, X.-H. Ma, P.-P. Cen, S.-C. Luo, Q. Shi, S.-R. Ma, Y.-W. Wu, C.-C. Zhang, G. Xie and S.-P. Chen, Dalton Trans., 2017, 46, 1207-1217.

4 W. Lustig, S. Mukherjee, N. Rudd, A. Desai, J. Li and S. Ghosh, Chem. Soc. Rev., 2017, 46, 3242-3285.

5 X.-Y. Ren and L.-H. Lu, Chin. Chem. Lett., 2015, 26, 14391445.

6 B. Li, H.-M. Wen, Y. Cui, W. Zhou, G. Qian and B. Chen, Adv. Mater., 2016, 28, 8819-8860.

7 W.-J. Shi, L.-Y. Du, H.-Y. Yang, K. Zhang, L. Hou and Y.-Y. Wang, Inorg. Chem., 2017, 56, 10090-10098.

8 L.-Y. Du, H. Wang, G. Liu, D. Xie, F.-S. Guo, L. Hou and Y.-Y. Wang, Dalton Trans., 2015, 44, 1110-1119.

9 Y.-Z. Li, H.-H. Wang, H.-Y. Yang, L. Hou, Y.-Y. Wang and Z.-H. Zhu, Chem.-Eur. J., 2018, 24, 865-871.

10 R.-W. Huang, Y.-S. Wei, X.-Y. Dong, X.-H. Wu, C.-X. Du, S.-Q. Zang and T. Mak, Nat. Chem., 2017, 9, 689-697.

11 Y. Li, H. Song, Q. Chen, K. Liu, F.-Y. Zhao, W.-J. Ruan and Z. Chang, J. Mater. Chem. A, 2014, 2, 9469-9473.

12 P.-C. Li, L. Zhang, M. Yang and K.-L. Zhang, J. Lumin., 2019, 207, 351-360.

13 O.-B. Le, S. Kitagawa and T. Uemura, J. Am. Chem. Soc., 2017, 139, 7886-7892.

14 D. Liu, J.-P. Lang and B. Abrahams, J. Am. Chem. Soc., 2011, 133, 11042-11045.
15 P. Ghorai, S. Banerjee, D. Nag, S. Mukhopadhyay and A. Saha, J. Lumin., 2019, 205, 197-209.

16 Q. Tang, S. Liu, Y. Liu, J. Miao, S. Li, L. Zhang, Z. Shi and Z. Zheng, Inorg. Chem., 2013, 52, 2799-2801.

17 W.-J. Gong, R. Yao, H.-X. Li, Z.-G. Ren, J.-G. Zhang and J.-P. Lang, Dalton Trans., 2017, 46, 16861-16871.

18 H. Guo, Y. Zhang, Z. Zheng, H. Lin and Y. Zhang, Talanta, 2017, 170, 146-151.

19 K. Sumida, D. Rogow, J. Mason, T. McDonald, E. Bloch, Z. Herm, T. Bae and J.-R. Long, Chem. Rev., 2012, 112, 724781.

20 J. Yu, L.-H. Xie, J.-R. Li, Y. Ma, J. Seminario and P. Balbuena, Chem. Rev., 2017, 117, 9674-9754.

21 N. Huang, K. Wang, H. Drake, P. Cai, J. Pang, J. Li, S. Che, L. Huang, Q. Wang and H.-C. Zhou, J. Am. Chem. Soc., 2018, 140, 6383-6390.

22 R.-W. Huang, Y.-S. Wei, X.-Y. Dong, X.-H. Wu, C.-X. Du, S.-Q. Zang and T. Mak, Nat. Chem., 2017, 9, 689-697.

23 Z. Lv, C. Liang, J. Cui, Y. Zhang and S. Xu, RSC Adv., 2015, 5, 18213-18217.

24 P. Ju, E. Zhang, L. Jiang, Z. Zhang, X. Hou, Y. Zhang, H. Yang and J. Wang, RSC Adv., 2018, 8, 21671-21678.

25 B. Parmar, Y. Rachuri, K. Bisht, R. Laiya and E. Suresh, Inorg. Chem., 2017, 56, 2627-2638.

26 G.-X. Wen, M.-L. Han, X.-Q. Wu, Y.-P. Wu, W.-W. Dong, J. Zhao, D.-S. Li and L.-F. Ma, Dalton Trans., 2016, 45, 15492-15499.

27 K. Wang, X.-L. Lv, D. Feng, L. Jian, S. Chen and J. Sun, J. Am. Chem. Soc., 2016, 138, 914-919.

28 J.-C. Jin, X.-R. Wu, Z.-D. Luo, F.-Y. Deng, J.-Q. Liu, A. Singh and A. Kumar, CrystEngComm, 2017, 19, 4368-4377.

29 B. Guo, L. Li, Y. Wang, Y. Zhu and G. Li, Dalton Trans., 2013, 42, 14268-14280.

30 M.-L. Zhang, Y.-J. Zheng, Z.-Z. Ma, Y.-X. Ren and J.-J. Wang, Polyhedron, 2018, 154, 473-479.

31 M.-L. Zhang, J.-J. Wang, Z.-Z. Ma and L. Qiao, New J. Chem., 2017, 41, 12139-12146.

32 M.-L. Zhang, Y.-J. Zheng, Z.-Z. Ma, Y.-X. Ren, J. Cao, Z.-X. Wang and J.-J. Wang, Polyhedron, 2018, 146, 180-186.

33 X. Wang, Y. Han, X.-X. Han, X. Hou, J.-J. Wang and F. Fu, New J. Chem., 2018, 42, 19844-19852.

34 W.-M. Chen, X.-L. Meng, G.-L. Zhuang, Z. Wang, M. Kurmoo, Q.-Q. Zhao, X.-P. Wang, B. Shan, C.-H. Tung and D. Sun, J. Mater. Chem. A, 2017, 5, 13079-13085.

35 S. Nagarkar, B. Joarder, A. Chaudhari, S. Mukherjee and S. Ghosh, Angew. Chem., Int. Ed., 2013, 52, 2881-2885.

36 G. M. Sheldrick, SHELXL-2014/7, Program for Crystal Structure Determination, University of Gottingen, Germany, 2014.

37 G. M. Sheldrick, SHELXL-2014/7, Program for Crystal Structure Refinement, University of Gottingen, Germany, 2014.

38 S.-B. Miao, Z.-H. Li, C.-Y. Xu and B.-M. Ji, Chin. J. Struct. Chem., 2016, 35, 1960-1966.

39 C. Qin, X.-L. Wang, L. Carlucci, M.-L. Tong, E.-B. Wang, C.-W. Hu and L. Xu, Chem. Commun., 2004, 16, 1876-1877. 
40 B. Barros, J. Chojnacki, A. Macedo Soares, J. Kulesza, L. Lourenço and S. Junior, Mater. Chem. Phys., 2015, 162, 364-371.

41 J. Meisner, J. Karwounopoulos, P. Walther, K. Johannes and N. Stefan, Molecules, 2018, 23, 432-446.

42 W. Hong, L. Li, R. Xue, X. Xu, H. Wang and J. Zhou, J. Colloid Interface Sci., 2017, 485, 175-182.

43 R. Lv, J. Wang, Y. Zhang, H. Li, L. Yang, S. Liao, W. Gu and X. Liu, J. Mater. Chem. A, 2016, 4, 15494-15500.

44 T. He, Y.-Z. Zhang, X.-J. Kong, J. Yu, X.-L. Lv, Y. Wu, Z.-J. Guo and J.-R. Li, ACS Appl. Mater. Interfaces, 2018, 10, 1665016659.

45 J.-N. Hao and B. Yan, New J. Chem., 2016, 40, 4654-4661.

46 S. Yao, T. Xu, N. Zhao, L. Zhang, Q. Huo and Y. Liu, Dalton Trans., 2017, 46, 3332-3337.

47 W.-J. Gong, R. Yao, H.-X. Li, Z.-G. Ren, J.-G. Zhang and J.-P. Lang, Dalton Trans., 2017, 46, 16861-16871.
48 X.-X. Wu, H.-R. Fu, M.-L. Han, Z. Zhou and L.-F. Ma, Cryst. Growth Des., 2017, 17, 6041-6048.

49 P. Ghosh, S. K. Saha, A. Roychowdhury and P. Banerjee, Eur. J. Inorg. Chem., 2015, 2851-2857.

50 B.-B. Lu, W. Jiang, J. Yang, Y.-Y. Liu and J.-F. Ma, ACS Appl. Mater. Interfaces, 2017, 9, 39441-39449.

51 D. Gao, Z. Wang, B. Liu, L. Ni, M. Wu and Z. Zhang, Anal. Chem., 2008, 80, 8545-8553.

52 S.-S. Jin, X. Han, J. Yang, H.-M. Zhang, X.-L. Liu and J.-F. Ma, J. Lumin., 2017, 188, 346-355.

53 Z.-J. Lin, H.-Q. Zheng, H.-Y. Zheng, L.-P. Lin, Q. Xin and R. Cao, Inorg. Chem., 2017, 56, 14178-14188.

54 Y. Rachuri, B. Parmar, K. Bisht and E. Suresh, Cryst. Growth Des., 2017, 17, 1363-1372.

55 S. Mukherjee, W. Lustig, N. Rudd, A. Desai, J. Li and S. Ghosh, Chem. Soc. Rev., 2017, 46, 3242-3285. 